Красинский Владислав Вячеславович

доктор юридических наук, член Общественного

консультативного научно-методического Совета

при ЦИК России

109012, г. Москва, Б. Черкасский пер. д. 4 стр. 2

Экстремистские интернет-ресурсы «Имарата Кавказ» и противодействие «информационному джихаду» северо-кавказского бандподполья

\title{
Extremist sites of «Imarate Kavkaz» and counteraction to «information jihad» North Caucasian bandit underground
}

В статье анализируется информационно-пропагандистская деятельность террористической организации «Имарат Кавказ». Рассматривается информационная инфраструктура северо-кавказского бандподполья и предлагаются меры противодействия терроризму и экстремизму в сети Интернет.

Ключевые слова: «Имарат Кавказ», «информационный джихад», северо-кавказское бандподполье, экстремистские и террористические сайты, противодействие терроризму.

In article information and propaganda activity of the terrorist organization «Imarat Kavkaz» is analyzed. Information infrastructure of North Caucasian bandit underground is considered and counteraction measures are offered terrorism and extremism on the Internet.

Keywords: Imarate Kavkaz, information jihad, North Caucasian bandit underground, extremist and terrorists sites, counteraction to terrorism.

Террористическая активность бандформирований на Северном Кавказе и резонансные теракты в различных регионах России свидетельствуют о том, что, несмотря на принимаемые государственными органами меры, бандподполье по-прежнему располагает значительной ресурсной и пособнической базой для совершения преступлений.

Процесс пополнения бандформирований происходит в непрерывном режиме. Наряду с социально-экономическими, политическими, идеологическими и иными факторами, важную роль в рекрутировании новых боевиков и информационно-пропагандистской поддержке террористического бандподполья Северо-кавказского региона (далее - СКР) играет Интернет. 
В северо-кавказском сегменте Интернета регулярно размещаются обращения лидеров бандформирований к «братьям по вере», звучат призывы к вооруженному джихаду и угрозы терактов в отношении сотрудников органов власти и управления ${ }^{1}$. Анализ контента популярных видеохостингов свидетельствует о наличии в свободном доступе значительного массива материалов об идеологии и террористической практике бандформирований CKP.

Активному использованию членами северо-кавказского бандподполья и их пособниками интернет-пространства способствуют следующие характеристики сети Интернет:

- малозатратный способ распространения информации и эффективный механизм обратной связи;

- простота подключения к сети (в том числе с ноутбуков, игровых консолей, смартфонов, планшетов, КПК и мобильных телефонов);

- высокая скорость передачи данных;

- экстерриториальный характер сети и наличие массовой аудитории пользователей;

- большой выбор интерактивных сервисов;

- высокая степень сохранения анонимности пользователя.

Возможности сети Интернет обусловливают ее использование в экстремистских и террористических целях для:

- дестабилизации политической и внутриконфессиональной обстановки в $\mathrm{CKP}^{2}$;

- расширения пособнической базы бандформирований и рекрутирования потенциальных исполнителей терактов ${ }^{3}$;

${ }^{1}$ По состоянию на май 2013 г. в федеральный список экстремистских материалов Министерства юстиции Российской Федерации включено 28 интернет-ресурсов Северокавказского бандподполья.

2 По мнению радикальных приверженцев «чистого ислама», решающим свидетельством единобожия (таухида) является абсолютное подчинение салафитсковаххабитской общине и вражда по отношению к инаковерующим («кафирам», «мунафикам», «муртадам», «мушрикам»). Салафитско-ваххабитское понимание принципа таухида требует устранения «власти неверных» и построения исламского государства. Тагутом (ложным поклонением помимо Аллаха) признается соблюдение законов, участие в политической жизни и формировании конституционных органов власти. 
- подготовки, организации и координации противоправной деятельности бандподполья ${ }^{4}$;

- финансирования террористической деятельности (как правило, применяются электронные платёжные системы Webmoney, «Яндекс деньги», Qiwi, Paypal, в отдельных случаях - сервис «Мобильный банк» операторов сотовой связи $)^{5}$;

- обучения участников бандформирований приёмам и методам изготовления оружия, ВВ, СВУ, осуществления шахидами терактов, способам противодействия правоохранительным органам ${ }^{6}$;

- распространения информации, направленной на пропаганду террористических и иных экстремистских идей (насильственного изменения конституционного строя, ксенофобии и др. $)^{7}$;

- рассылки анонимных сообщений об угрозах совершения терактов.

В целях обеспечения собственной безопасности члены бандподполья и их пособники комплексно используют меры конспирации (анонимные

3 При опросе правоохранительными органами ряда явившихся с повинной боевиков были получены сведения о том, что на их решение присоединиться к террористической деятельности бандформирований существенное влияние оказали материалы экстремистских сайтов вилаятов «Имарата Кавказ».

4 C помощью сайтов происходит размещение пропагандистских материалов и инструктивных указаний руководства «Имарата Кавказ» «валиям»и «кадиям» вилаятов, «амирам» секторов бандподполья, а также отчетной документации о ведении джихада. На сайтах Kavkaz-Center.com, VDagestan.com и Badr-tawhid.info выложены сводки джихада за каждую неделю, месяц и год по хиджре.

5 Раздел «Пожертвования на пути Аллаха» присутствует на сайтах Nuruddin.info, Daavat.me и др. Сбор финансовых средств для оказания помощи бандподполью осуществляется как «выселившимися» участниками БФ и их пособниками, так и членами «Тюремных джамаатов» в учреждениях УИН.

6 Так, на сайте «Вилаята Галгайче» Hunafa.com размещены «Методические рекомендации по мерам безопасности в ходе ведения джихада против федеральных сил», Рекомендации «О безопасности и защите информации в Интернете». Участники бандформирований инструктируются о мерах конспирации при пользовании средствами связи, сетью Интернет, об экипировании, военно-полевой медицине, организации засадных действий. На сайте муджаидов «Объединенного Вилаята Кабарды, Балкарии и Карачая» Islamdin.biz приведена технология изготовления инерционного датчика «Гарпун» для минирования автомобилей. Pecypc VDagestan.net содержит сведения об изготовлении аммонала и детонаторов. Сайт Badr-tawhid.info содержит информацию о способах изготовления «коктейля Молотова». На сайте Kavkaz-Center.com указаны технологии подключения к блокированным сайтам на территории РФ.

7 Так, на сайте http: circassia.forumieren.de была размещена экстремистская статья о восстановлении государственности независимой Черкессии. На платформе «Одноклассники» выявлены тематические группы «Ура, я не осетин», «Protiv osetin» и др., пропагандирующие межнациональную рознь. Среди участников бандформирований СКР наибольшей популярностью пользуются видеолекции таких идеологов радикального ислама, как Саид Абу Саад («Бурятский»), Анзор Астемиров, Амир Сейфулла («Губденский»), Хаттаб, Мухаммед Багаутдин. 
прокси-серверы, криптографические программы и программы «маршрутизаторы», выход в сеть из пунктов коллективного доступа, мобильный интернет с обезличенных Sim-карт и др.).

Как правило, террористическая и иная экстремистская деятельность в Интернете («информационный джихад») осуществляется с помощью трех основных видов информационных ресурсов:

а) социальные сети, блоги и форумы (профили «Имарата Кавказ» в сетях Facebook, «ВКонтакте», «Одноклассники», в «Живом Журнале», сервисах микроблогов Twitter, а также на специализированных форумах (саляф-форумах, исламских форумах «независимых» информационных агентств - UmmaNews, «Джамаат», «ИК-Медиа», «ИмамТВ», «АланИнформ»);

б) сайты «вилаятов» «Имарата Кавказ» (Kavkaz-Center.com, Kavkaz.org.uk, Camagat.com, Guraba.info, Hunafa.com, Islamdin.biz);

в) чаты (Kavkazchat, IRW), мгновенные сервисы передачи информации и интернет-пейджеры.

Сложившаяся информационная инфраструктура северо-кавказского бандподполья позволяет пропагандистам и пособникам бандформирований инициировать обсуждение экстремистских материалов, их индексирование поисковыми машинами («разгон») и осуществлять первичное изучение пользователей.

Возможности социальных сетей и форумов активно используются для организации финансирования северо-кавказского бандподполья. В частности, на платформах «Одноклассники» и «В контакте» присутствуют тематические группы, модераторы которых призывают пользователей принять участие в сборе «пожертвований» для «братьев по вере». Целями подобных закрытых групп являются оказание «помощи семьям муджаидов, шахидов, поддержка исламскому призыву и «делу джихада»»». Для перечисления денежных средств боевикам указаны номера счетов системы «Яндекс. Деньги», номера мобильных телефонов, карт Сбербанка и Россельхозбанка. 
Общение в форумах, чатах и микроблогах используется бандподпольем для вербовочного изучения участников обсуждений, проявивших интерес к экстремистской идеологии, произвольного и манипулятивного толкования коранических аятов и хадисов Пророка, интерпретации джихада как войны с инаковерующими, обвинений представителей традиционного для СКР тариката накшбандийа, кадирийа и шазилийа в невежестве (джахилии), неверии (куфре) и язычестве (шикре).

Интернет-ресурсы бандподполья СКР отличаются привлекательностью графического оформления, оперативностью обновления, продуманностью интерфейса, приоритетной ориентацией на молодежь. Особенностями их технической организации являются: регистрация доменов на подставных лиц, размещение на серверах зарубежных провайдеров, наличие «зеркал» веб-ресурсов с частично измененной именной группой.

По содержанию информационные материалы террористического бандподполья СКР можно условно поделить на три основные категории:

а) видеоролики со сценами совершения боевиками преступлений (терактов, убийств сотрудников правоохранительных органов и др.);

б) обращения участников бандформирований (угрозы должностным лицам органов власти и управления, сотрудникам правоохранительных органов, присяги «амирам» «секторов» и «вилаятов» и др.);

в) материалы дезинформационного характера (о социальнополитической обстановке, общественных и государственных деятелях и др.).

По направленности экстремистской пропаганды можно выделить следующие формы «информационного джихада» с использованием сети Интернет:

- размещение мультимедийных материалов с критикой российского руководства, органов власти СКР, формированием нетерпимости по отношению к России («кафирской Русне»), пропагандой построения государства «Имарат Кавказ» с шариатской формой правления; 
- распространение фото и видео-изображений действующих и нейтрализованных участников бандгрупп и результатов «шахидских операций»; «героизация лидеров джихада» и размещение информации о них в разделе «Геноцид»;

- пропаганда «культуры и истории джихада» (обоснование преемственности современного джихада и вооруженной борьбы имамов Гази-Магомеда, Шамиля; история салафитской уммы, поэзия «истинных мусульман»- «нашиды»);

- индивидуальная агитационная обработка пользователей путем распространения выборочных отмененных аятов, якобы призывающих к совершению преступлений, фетв по вопросам джихада и вынесения такфира, а также применения аятов о многобожниках и неверных в отношении мусульман;

- рассылка электронных писем целевой аудитории с призывом к исправлению акиды, «чистому» исламу, джихаду против куфра и ширка, к освобождению оккупированной кафирами исламской территории (дар альислам), а также рассылка террористических угроз в адрес должностных лиц органов власти и управления, сотрудников правоохранительных структур, представителей СМИ и официального ислама;

- разработка и распространение сетевых компьютерных игр, пропагандирующих идеологию вооруженного джихада (компьютерная игра «Bamut») $)^{8}$.

Следует отметить, что вместо противодействия экстремистской идеологии северо-кавказского бандподполья органы власти и управления занимаются, главным образом, борьбой с экстремистскими и террористическими сайтами.

Действующее законодательство Российской Федерации позволяет осуществлять работу по ограничению доступа к интернет-ресурсам,

\footnotetext{
${ }^{8}$ Решением Ленинского районного суда г. Грозный от 14.04.2011 г. компьютерная игра «Bamut» внесена в федеральный список экстремистских материалов.
} 
используемым членами бандподполья и их пособниками, в рамках двух основных направлений:

1. Блокирование сетевых адресов или прекращение делегирования домена в случае расположения интернет-ресурса в зонах «ru» и «рф» ${ }^{9}$.

2. Фильтрация трафика на пограничных маршрутизаторах интернетпровайдеров.

При организации работы по выявлению и пресечению террористической и иной экстремистской деятельности в сети Интернет правоохранительные органы сталкиваются с рядом проблем правового и организационного характера, затрудняющих привлечение к уголовной ответственности абонентов сети, в том числе вынашивающих намерения совершить террористический акт или вступить в ряды бандподполья.

Так, в числе проблем правового характера можно отметить:

1. Отсутствие унифицированных международно-правовых позиций в отношении определения понятий «интернет-ресурсы», «экстремизм», «экстремистская организация», «экстремистские материалы» и «двойные» стандарты в вопросах экстрадиции и уголовного преследования террористов.

2. Отсутствие международной договорной базы, регулирующей порядок прекращения функционирования сайтов, содержащих противоправную информацию, и блокирования доступа к ним.

3. Несовершенство законодательного регулирования правового статуса и ответственности субъектов, осуществляющих деятельность в сети и предоставляющих доступ к Интернету (провайдер, администратор (владелец)

9 Так, 06.07.2010 г. Верховный суд КБР принял решение о признании веб-ресурса www.islamdin.com экстремистским материалом с блокированием доступа. 26.12. 2011 г. Нальчикский городской суд признал экстремистским и запретил деятельность веб-ресурса www.djamaattakbir.com. 15.03.2011 г. Советский районный суд г. Махачкалы признал экстремистскими сайты Salafiti.ru, Fisadilillahi.com, Abuhurayra.wen.ru. 13.04.2012 г. и 04.05.2012 г. этим же судом признаны экстремистскими сайты Guraba.com., VDagestan.com и VDagestan.info. 12.04.2010 г. и 24.06.2010 г. решениями Магасского районного суда РИ запрещена деятельность экстремистских сайтов Hunafa.com и Ingushetia.org. Этим же судом 09.11.2012 г. признаны экстремистскими ресурсы Rionline.ru и Angusht.com. 24.09.2012 г. Октябрьский районный суд г. Ставрополя признал экстремистским сайт Ansardin.wordpress.com

Все указанные веб-ресурсы признаны экстремистскими с блокированием доступа и внесены в Федеральный список экстремистских материалов МЮ РФ. 
сайта, хостинг-провайдер), что не позволяет разграничить их ответственность за размещение противоправной информации.

4. Правовые ограничения, предусмотренные ст. 8 ФЗ «Об оперативнорозыскной деятельности» на проведение отдельных оперативно-розыскных мероприятий в отношении подозреваемых или обвиняемых в совершении преступлений экстремистской направленности небольшой тяжести (ч.1 ст. 280 УК РФ «Публичные призывы к осуществлению экстремистской деятельности», ч.1 ст. 282 УК РФ «Возбуждение ненависти либо вражды, унижение человеческого достоинства»).

К проблемам организационного характера относятся:

1. Особенности технической организации сети Интернет, которые позволяют регистрировать доменные имена сайта в одной стране и размещать информацию в другой, что создает затруднения при выявлении и ликвидации сетевых центров (серверов, доменов, веб-сайтов) бандподполья.

2. Возможность подключения к Интернету лиц, вынашивающих террористические и иные экстремистские намерения, из пунктов коллективного доступа, где не ведется отождествление личности посетителей и не установлены камеры видеонаблюдения.

3. Отсутствие четкой организации и оперативного сопровождения экспертного процесса по экстремистским материалам, размещенным в Интернете (использование невалидных методик, привлечение экспертов ненадлежащей квалификации, отсутствие работы с экспертами и судейским корпусом).

4. Отсутствие четкой методики формирования Федерального списка экстремистских материалов (неоднократное вынесение судебных решений по одним и тем же веб-ресурсам, с одной стороны; непризнание экстремистскими материалов из Федерального списка с измененными реквизитами (год издания, наименование издательства) и их электронных копий, с другой; некорректное указание сетевых адресов и т.п.) ${ }^{10}$.

10 Так, ресурс Shamilonline.org четырьмя разными судами в разное время признавался экстремистским, сайты VDagestan.com, VDagestan.info, Djamagat.wordpress.com - признавались экстремистскими дважды. 
C учетом изложенного, предлагается комплекс взаимосвязанных организационно-правовых, научно-технических, кадровых, методических и информационно-аналитических мер по совершенствованию работы компетентных государственных органов, направленной на выявление и пресечение террористической и иной экстремистской деятельности бандподполья в сети Интернет.

Организационно-правовое обеспечение выявления и пресечения террористической и иной экстремистской деятельности северо-кавказского бандподполья в сети Интернет должно включать: участие специалистов правоохранительных органов в разработке законодательных, подзаконных и межведомственных актов в рассматриваемой области ${ }^{11}$; взаимодействие с зарубежными партнерами, в интернет-сегментах которых действуют экстремистские сайты; координацию и взаимодействие оперативных и следственных подразделений, подразделений программ содействия, НАК, пресс-служб и информационных центров федеральных и региональных органов власти.

Научно-техническое обеспечение предполагает планирование, проведение, координацию и внедрение результатов НИР и НИОКР по разработке и модернизации программно-аппаратных средств сетевого мониторинга, систем фильтрации и автоматизированного перевода мультиязычной информации, анализаторов изображения в социальных сетях, рост уровня технической оснащенности и внедрение научно обоснованных рекомендаций по повышению эффективности деятельности на направлении информационного противоборства терроризму и экстремизму.

11 Речь идет о внесении изменений в Федеральный закон «Об информации, информационной технологиях и защите информации» (включение терминов «интернет», «интернет-ресурс», «регистратор доменного имени», «контент». «хостинг»), Федеральный закон «О связи» (включение терминов «услуга хостинга», «электронная почта»), Правила взаимодействия операторов связи с уполномоченными государственными органами, осуществляющими оперативно-розыскную деятельность, утвержденные Постановлением Правительства РФ от 27 августа 2005 г. № 538, Правила оказания телематических услуг связи, утвержденные постановлением Правительства РФ от 9 октября 2007 г. № 575 (в части исключения анонимности пользователей в пунктах коллективного доступа и запрета использования анонимайзеров и программ-маршрутизаторов) и в Уголовный кодекс (в части усиления уголовной ответственности по составам преступлений, предусмотренным ч. 1 ст. 280 и ч. 1 ст. 282 УК РФ). 
Кадровое и методическое обеспечение охватывает приоритетное комплектование подразделений правоохранительных органов по линиям обеспечения информационной безопасности, программ содействия, информационного противоборства, подготовку и повышение квалификации экспертов-психологов - лингвистов, ІТ-специалистов (в том числе с углубленным знанием религиоведения, арабского и турецкого языков), разработку программ обучения и необходимых методических материалов.

Информационно-аналитическое обеспечение должно включать своевременное предоставление руководству государственных органов и заинтересованных подразделений правоохранительных органов материалов, необходимых для проведения государственной политики РФ в области информационного противоборства терроризму и экстремизму, организации и осуществления оперативно-служебной деятельности на данном направлении, систематическую подготовку контрпропагандистских материалов (прежде всего, фото- и видео), рассчитанных на различные целевые аудитории, их грамотное анонсирование и активное информационное продвижение в «топы» поисковых систем.

Успешное осуществление предложенных мер зависит от наличия достаточного финансового и ресурсного обеспечения.

Следует констатировать, что в комплексе принимаемых государственными органами мер по противодействию терроризму и экстремизму на территории СКР длительное время превалировала силовая составляющая. Главным, а зачастую - и единственным инструментом борьбы с бандподпольем являлись контртеррористические операции и оперативнобоевые мероприятия.

Однако опыт применения такой стратегии показал, что бандподполье достаточно быстро восстанавливает систему координации террористической деятельности, свою численность и боеспособность, нарушенную после нейтрализации бандглаварей различного уровня. В этих условиях наиболее эффективным представляется системный, комплексный подход в области 
противодействия терроризму и экстремизму, основанный на информационнопропагандистской и профилактической работе с местным населением, и особенно с молодежью.

В настоящее время повышению эффективности принимаемых мер по противодействию терроризму и экстремизму в СКР могут способствовать:

проведение и внедрение результатов научных исследований, связанных c разработкой и реализацией информационно-пропагандистских мероприятий антиэкстремистской и антитеррористической направленности;

создание в СКР оперативных механизмов информационнопропагандистского обеспечения противодействия терроризму и иным формам экстремизма, восстановления доверия населения к правоохранительным органам;

разработка и реализация долгосрочной Стратегии национальной политики в СКР;

содействие внутри- и межконфессиональному диалогу;

разработка и последовательное осуществление комплексных программ социально-экономического развития региона, направленных на создание рабочих мест и привлечение молодых специалистов;

организационно-правовое укрепление комиссий по адаптации бывших участников бандподполья, развитие программ по интеграции в мирную жизнь (переезд, трудоустройство, социальная защита) лиц, возвратившихся из мест лишения свободы;

амнистия участников бандформирований, не совершивших тяжких преступлений, добровольно сложивших оружие и готовых сотрудничать со следствием;

разработка и реализация в религиозных и светских учебных заведениях образовательных программ, направленных на противодействие религиозному радикализму и экстремизму.

Успешное противодействие «информационному джихаду» северокавказского бандподполья невозможно без разработки и проведения 
эффективной молодежной политики, реализации антикоррупционных программ, последовательной государственной политики в области исламской культуры и образования.

Красинский Владислав Вячеславович доктор юридических наук, член Общественного консультативного научно-методического Совета при ЦИК России

109012, г. Москва, Б. Черкасский пер. д. 4 стр. 2 